\title{
Insularidade e identidade em Onésimo Teotónio Almeida: da cultura à literatura
}

\author{
José Cândido de Oliveira Martins ${ }^{*}$
}

A janela dava para o mar e às vezes havia uma ilha ao longe

Fernando Pessoa, O marinheiro

\begin{abstract}
Que é necessário sair da ilha para ver a ilha, que não nos vemos se não nos saímos de nós. José Saramago, O conto da ilha desconhecida
\end{abstract}

\section{Ponto de partida: o imaginário intemporal da ilha}

Num tempo de acelerada globalização, e sem paradoxo algum, vivemos tempos de ampla questionação da(s) identidade(s), a partir de muitos ângulos de abordagem. Por vezes, a contraposição entre o local e o global pode proporcionar espaços de fecunda problematização. Esse é o caso particular da identidade cultural de espaços territorialmente circunscritos, na sua relação ou contraposição com outros territórios de mais ampla e aberta geografia. As ilhas sempre foram, ao longo dos séculos, motivos estéticos de continuada inspiração poético-literária e artística (da poesia e da narrativa à pintura, à música e ao cinema); mas também de prolongada reflexão filosófica, cultural e identitária. Isso deve-se sobretudo às particularidades e à magia deste tipo de território, com sua singular e variável morfologia geográfica, enquanto signo, metáfora, símbolo, arquétipo e tema, geradores de um poderoso imaginário insular, daí se originando uma riquíssima e complexa carga mítica, simbólica, cultural, psicanalítica e até turística.

Isso aconteceu independentemente de se tratarem de ilhas reais ou imaginárias, referenciadas ou perdidas, transformando-se, ambiguamente, em lugares primordiais, de refúgio e de segurança, mas também de longínquo isolamento (desde a origem etimológica), de cativeiro ou deportação (deportatio ad insulam) e ainda de morte, como signo da descontinuidade. Em muitos casos, as ilhas também se metamorfoseiam em espaços de aparições e de tormentos, mas igualmente de aventura e de peregrinação (as peregrinationes medievais como a Navegação de São Brandão, por exemplo), de exílio ou de sonho, da paradigmática Utopia de Thomas Morus

Doutor em Humanidades, com especialização em Teoria da Literatura e professor da Faculdade de Filosofia e Ciências Sociais da Universidade Católica Portuguesa, Braga, Portugal. E-mail: martins.candido@gmail.com. 
à ficção de Daniel Defoe e de Stevenson, das ilhas bem-aventuradas à camoniana Ilha dos Amores. ${ }^{1}$

Pelo sugerido, interligando a terra e o mar, e representando o outro e o estranho, por oposição a outra(s) ilha(s) ou continente, sabemos como a ilha se erigiu desde o mítico Ulisses e seus avatares - em espaço privilegiado de navegação, de sociedade alternativa e, consequentemente, em lugar tópico do pensamento e da criação multisseculares, da Antiguidade clássica aos nossos dias. ${ }^{2}$ Dentro do tema amplo e complexo da ilha enquanto desafio de reflexão identitária, na literatura e cultura portuguesas, avulta o caso singular das ilhas dos Açores como espaço histórico-cultural, por um lado; e, por outro, ao nível da produção ensaística e mesmo da criação literária, escolhemos um ensaísta bem representativo desse filão temático, pensado a partir da diáspora - Onésimo Teotónio Almeida, natural dos Açores, professor e investigador na Brown University, em Providence (Estados Unidos da América).

Ora, entre outros domínios de pesquisa, a reiterada escrita reflexiva deste autor tem-se detido, com assinalável insistência, no tema da identidade cultural, tomando as ilhas açorianas como caso exemplar - e é esse justamente o ponto que nos importa: analisar como a matriz da insularidade se relaciona com a ideia de construção da identidade cultural, na perspectiva de Onésimo Teotónio Almeida, desde ensaio académico até à criação literária. $\mathrm{O}$ autor tem-se debruçado sobre o tema obsessivamente, em inúmeros textos dispersos, só parcialmente recolhidos em livro. Por isso mesmo, não surpreende a sua reacção quando o convidam e interrogam como se ele abordasse a questão pela primeira vez, ignorando o já publicado - parafraseando Umberto Eco, poderíamos afirmar que, para certos olhos apressados, não há nada de mais inédito do que aquilo que já foi publicado. ${ }^{3}$

\footnotetext{
Entre os lugares imaginários da geografia literária de muitos séculos, ocupam lugar preponderante várias ilhas, umas mais reconhecíveis do que outras, como podemos contatar no Dicionário de lugares imaginários, de Alberton Manguel \& G. Guadalupi (2013): Ilha dos Abençoados, Ilhas das Abóboras, Ilha do Acaso, Ilhas Afortunadas, Ilha das Águas da Morte, Ilha dos Pinguins, Ilha de Alcina, Ilha do Amanhã, Ilha Amorfa, Ilha Ardida, Ilha da Areia Verde, Ilha das Árvores Móveis, Ilha Assombrada, Ilha de Axel, Ilha da Baranka, Ilha de Bingfield, Ilha das Borboletas, Ilha Corcovada Bossard, Ilha de Bran, Ilhas Maravilhosas Brisevent, Ilha da Paz Broolyl, Ilha dos Burros Dourados, etc. Este é apenas o elenco das duas primeiras letras do alfabeto.

2 Para uma breve visão de síntese, basta consultar alguns dicionários de símbolos ou obras de referência similar; e ainda significativos volumes temáticos como o da revista Les Lettres Romannes (AA. VV., 2012) e o dossiê "L'île dans la Littérature"; ou o organizado por J.-C. \& Marimoutou e J.-M. Racault (1995), L'Insularité, thématique et répresentations; e ainda o recente número da canadiana Island Studies fournal, com uma secção especial dedicada ao tema - "Reframing Islandness: Thinking with the Archipelago", publicação oficial da International Small Islands Studies Association (ISISA).

3 Dada a considerável produção ensaística de Onésimo Teotónio Almeida (publicada ou ainda inédita) sobre o tema em questão - em natural relação com o curso de "Ideologies of National Identities" que lecciona na sua universidade, não temos a pretensão de, no espaço de um breve texto, analisar criticamente todos os seus ensaios e intervenções; mas, selecionando alguns dos trabalhos representativos, apresentar o seu pensamento nesta matéria complexa, que, consabidamente, tem suscitado tão abundante bibliografia crítica. Se os ensaios do autor sobre a matéria
} 
Potenciando o diálogo de representações interculturais ou o confronto com o Outro, pode a condição de insularidade transformar-se numa interrogação ontológica sobre a identidade cultural? Para maior clareza, e seguindo a evolução do pensamento do autor, é metodologicamente recomendável partir do geral para o particular, isto é, da temática da identidade cultural para o questionamento da existência da açorianidade, concebida como a face particular da insularidade, face à realidade mais plural da identidade cultural portuguesa.

Como recordava Onésimo Teotónio Almeida (2013b) recentemente, numa crónica intitulada "Estórias do cerco da ilha", mau grado o isolamento e a conjugação da exiguidade (variável) do território e ainda a distância em relação ao continente, vários factores podem ter um peso considerável na história de ilhas como os Açores. As ilhas são sobretudo espaços onde se confrontam imagens ou visões identitárias, as "de fora" e das "de dentro". Vejamos.

\section{Identidade cultural, vexata quaestio}

Ao perspectivar a velha e controversa questão da identidade cultural em vários dos seus ensaios, Onésimo Teotónio Almeida introduz, desde logo, algumas ressalvas e, com essa preocupação metodológica e clarificadora, demarca-se assumidamente de alguns equívocos resultantes da polissemia associada à discussão. Com esses cuidados, procura distanciar-se de conceitos problemáticos que não contribuem para a desejável clareza da discussão, por um lado; e por outro, censura o distanciamento das ciências sociais face a esta questão, sobretudo quando contrasta com a crescente popularidade do conceito de identidade. ${ }^{4}$

Uma coisa é certa, em tempos de acentuado cosmopolitismo e de crescente globalização, são muitos e prestigiados os autores a reclamar a pertinência sobre o debate crítico da identidade cultural, a diversos níveis. Consabidamente, a questão é muito antiga e não isenta de complexidade. Para preparar o debate rigoroso, Onésimo Teotónio Almeida tem o meritório cuidado de estabelecer algumas clarificações prévias e absolutamente essenciais, como veremos.

Em primeiro lugar, sobrevém o problema teórico do conceito de identidade, que, sendo labiríntico por natureza, desencadeia um vasto e intrincado conjunto de questões derivadas. Aliás, por essa e outras razões que não interessa elencar,

constituiriam um significativo e desejável volume de que o livro recente, A obsessão da portugalidade (AlmEIDA, 2017) reúne apenas uma pequena parcela desses estudos, a sua análise aprofundada exigiria um estudo de dimensão similar, e não um breve artigo. Para um enquadramento propedêutico, acrescente-se que ainda recentemente Miguel Real (2011, p. 966-1003) traçou uma panorâmica do contributo de Onésimo Teotónio Almeida na história do pensamento português contemporâneo.

4 Cf. os estudos, em diferentes perspectivas, de Homi B. Bhabba (1990), Nation and narration; de Benedict Anderson (1991), Imagined communities; de Anthony Smith (1991), National identity; e de Anne-Marie Thiesse (2000), A criação das identidades nacionais, a par de tantos outros trabalhos congéneres no domínio dos estudos culturais. 
não é por acaso que múltiplos intelectuais e cientistas sociais se mostram "refractários ao tratamento da questão da identidade”, como nos lembra Onésimo Teotónio Almeida (2009, p. 63). Impõe-se hoje, no campo das ciências sociais, perspectivar a "identidade" como um conceito dinâmico - com base na noção natureza antropológica de "cultura" (do clássico E. B. Taylor) -, pois as sociedades são realidades manifestamente evolutivas, ao mesmo tempo que essa noção se deve mostrar equidistante de visões estreitas e fixistas.

Desde logo, não se deve confundir identidade pessoal e identidade colectiva, embora possam existir relações. Ainda mais importante, num discurso nem sempre isento de contaminação política e ideológica, também se devem distinguir identidade nacional, conjunto de elementos que pretensamente aproximam uma comunidade; e expressão ou conceito de carácter nacional, que tende a incidir sobre padrões de comportamento e surge frequentemente conotada com patriotismo. Em relação ao seu uso actual, o primeiro conceito continua a empregar-se, mas a segunda expressão, tendo sido objecto de indevidos aproveitamentos ideológicos, é hoje genericamente repudiada.

Face ao afirmado, faz todo o sentido a preocupação de Onésimo Teotónio Almeida (2009) quando, em estudos como "Identidade cultural: desdobrando polissemias em busca da clareza”, o investigador insiste na absoluta necessidade de não se confundir identidade cultural com os conceitos de nacionalismo e patriotismo, sob pena de minar definitivamente qualquer debate ou pesquisa séria sobre o assunto. Deste modo, procura-se distinguir claramente três sentidos habituais nos debates sobre a questão, advertindo, primeiro, que "a coexistência destes três sentidos actuais do termo identidade torna qualquer debate potencialmente viciado à partida"; ao mesmo tempo que chama a atenção, em segundo lugar, para a impossibilidade de se evitar o conceito de identidade (cultural ou nacional)" (AlmEIDA, 2009, p. 58, 59). Convém enunciar claramente esses sentidos correntes: "1. Identidade como brio nacional, ou patriotismo; 2. Identidade como carácter nacional, ou padrões de comportamentos colectivos de um povo, nação, ou país, estruturados ao longo de séculos; 3 . a união de um povo congregado em torno de vontades e ideais comuns" (AlmEIDA, 2009, p. 52).

Nesse esforço de clarificação semântica, e pela mesma ordem, teríamos três sentidos do conceito axial de "identidade": 1) orgulho patriótico ou nacionalismo (identificação afectiva), com forte carga ideológica; 2) carácter nacional, alicerçado na história, expressão hoje com má reputação, mercê dos excessivos aproveitamentos racionalistas de que foi alvo; e 3) colectivo, com vista ao futuro imediato. Ora, como é bom de ver, são sentidos bem distintos, cuja óbvia polissemia por vezes escapou até a grandes espíritos que se debruçaram sobre estas questões, gerando por vezes discussões pouco esclarecidas e quase estéreis, além inquinar a desejável clareza da reflexão crítica.

Como se isto não fosse fundamental para a preparação do bom debate argumentativo, é talvez a primeira vez, neste referido ensaio de Onésimo Teotónio Almeida 
(2009), que em português se aborda um aspecto importante do conceito de identidade: o facto de ser diferente o que dizemos sobre o passado e o que dizemos sobre o futuro, numa dialéctica entre o ideológico e o utópico, que articula o olhar conservador com a perspectiva de futuro. Assim sendo, a questão da identidade, para este autor, é sempre dupla: "a) do modo de estar de um povo (é perigoso falar-se em 'ser' e por isso prefiro 'estar') detectável ao longo do seu percurso histórico; b) o modo como um povo se organiza colectivamente em relação àquilo que pretende realizar no futuro" (AlmEIDA, 2009, p. 59). Embora intimamente interligadas, quando falamos de identidade focamos especialmente a segunda dimensão.

Em segundo lugar, em vários dos seus estudos sobre o tema, Onésimo Teotónio Almeida demarca-se de uma certa tradição crítico-interpretativa que fez escola na cultura portuguesa, ao assumir uma oposição frontal e justificada face à chamada "filosofia portuguesa", numa postura anti-essencialista. Para isso, de modo frontal e justificado, critica as várias ideias apresentadas pelos mentores dessa concepção, particularmente em Filosofia portuguesa: alguns equivocos (1985). Ao desmontar as teses de autores muito influentes a partir da primeira metade do séc. XIX, de Teixeira de Pascoaes (Arte de ser português) a António Quadros (de O espirito da cultura portuguesa) ou Orlando Vitorino (cf. MARTins, 2017). Mais concretamente, para autores como Onésimo Teotónio Almeida, não é possível arvorar o conceito de "saudade" em matriz axial e imutável de uma pretensa "alma nacional". 5

Definitivamente, não é sustentável generalizar traços ou virtudes que por si só definam o "carácter português" (AlmeidA, 1985). Como também não é admissível, numa contestável falácia naturalista, a partir de certos traços históricos, abstrair indutivamente certas características para o plano essencialista - do ser para o dever ser, isto é, do plano histórico para o ontológico: "outra [coisa] é a transformação dessas supostas características culturais em essências com carácter metafísico, isto é, de natureza ôntica, imutável e determinista, como fazem Teixeira de Pascoaes no início do século e António Quadros continua fazendo hoje" (AlmeidA, 1991, p. 497). Por outras palavras, anos antes do contributo de Boaventura Sousa Santos (1999) sobre o assunto, já Onésimo Teotónio Almeida, na década de 1980, se manifestava "contra o determinismo fixista do essencialismo nacional” (ALMEIDA, 2009, p. 53).

Como vemos, com esse desiderato problematizador, e à luz de uma perspetiva empírico-racionalista, Onésimo Teotónio Almeida contesta a inclinação ou "obsessão das filosofias nacionais" e a ideia subjacente de um tipicismo decorrente de circunstâncias histórico-políticas (AlmeidA, 1985, p. 254). Ao mesmo tempo, desmonta a ideia de que a criação cultural (das artes à religião) de um país espelharia sempre e necessariamente a personalidade idiossincrática desse país, captando o

\footnotetext{
5 Neste domínio, revelam-se bem eloquentes os quatro ensaios na terceira parte de $A$ obsessão da portugalidade (AlMEIDA, 2017, p. 153-227), em torno do tema multissecular da saudade e concedendo amplo destaque às reiteradas teses sobre o tema por parte de ensaístas auto-intitulados como pertencentes à "filosofia portuguesa”.
} 
"génio da raça". Ora, em Portugal ou em outra realidade histórico-cultural, a filosofia não pode confinar-se a ser a expressão desta alma colectiva, tantas vezes expressa numa "elaboração literário-poética de intuições", para recorrermos à sua conseguida formulação. Na captação de "características culturais portuguesas", pretensamente representativas de uma "mundividência portuguesa", constitui-se assim para certa tradição crítico-cultural um "modelo estético-ético", desenvolvido com várias debilidades, desde logo de natureza epistemológica, em detrimento de uma actividade concebida em termos racionais e universais (ALMEIDA, 1985, p. 245-246).

Por fim, inter-relacionadamente e ainda dentro de uma problematização genérica da questão da identidade cultural, e num afã igualmente clarificador das distintas perspectivas de aproximação ao tema ao longo de mais de um século, Onésimo Teotónio Almeida sistematiza algumas das principais tendências críticas em três grandes conjuntos de intelectuais. Assim, em primeiro lugar, destacam-se os adeptos da mencionada "filosofia portuguesa", agrupando nomes tão diversos como Teixeira de Pascoaes, Leonardo Coimbra, António Quadros, Álvaro Ribeiro ou Orlando Vitorino. Num ideário próximo do movimento cultural em torno da revista Águia, do início de Novecentos, estes e outros pensadores defendiam a existência de uma filosofia portuguesa, partindo do muito discutível pressuposto da demarcação de filosofias nacionais. Com isso, não só pretendiam salientar especificidades únicas do pensamento português, mas também afirmar a configuração de um "génio da raça" lusa, sendo hoje condenáveis todas essas tentativas de orientação essencialista (ALMEIDA, 1985).

No polo oposto desta postura que tende para um discurso tantas vezes de tonalidade místico-simbólica, erguem-se os cientistas socais, exemplificados pela perspectiva de Boaventura Sousa Santos (1999), entre outros, que reagiram frontalmente contra os pressupostos, os métodos e o discurso de um conhecimento não assente num rigor epistemológico e em estudos empíricos. ${ }^{6}$

Esta perspectiva tem a ser favor a caução ou auctoritas da instituição universitária, embora se possa argumentar - como relembra Onésimo Teotónio Almeida - que nas ciências sociais, ao contrário do que parecem fazer crer os seus investigadores, "não existem leis nem constantes universais do tipo das leis da física" (Almeida, 2009, p. 53). Ao mesmo tempo, também não se torna muito exequível elaborar investigações assentes em trabalhos estatísticos ou em aspectos mensuráveis. Talvez por isso, os cientistas sociais ostracizaram os conceitos ou expres-

\footnotetext{
6 É conhecido o modo como o influente sociólogo Boaventura de Sousa Santos, sem citar Onésimo T. Almeida, se mostra contundente face a algumas teses pretensamente ontológicas de uma psicologia coletiva dos portugueses. Além de sublinhar o "excesso mítico da interpretação sobre a sociedade portuguesa", sustenta, consequentemente, que "os discursos convencionais sobre a 'identidade nacional' ou sobre o 'carácter nacional' têm sido construídos a partir de um genius loci mitificado, abstracto e mistificados” (SANTOS, 1999: p. 50, 54). As representações da portugalidade mostram-se um filão plural, controverso e inesgotável até à actualidade (cf. MATTOso, 2001; BARATA, 2011).
} 
sões como o de "carácter nacional", na medida em que não encaixam na sua filosofia científica. ${ }^{7}$

Finalmente, entre os dois extremos ou tendências sumariamente referidas, sobressai um ensaísmo filosófico-cultural, propondo uma visão histórica e reflexiva ponderada, que ora se demarca dos excessos das reflexões ontológicas da "filosofia portuguesa", ora das pretensões científicas dos estudiosos das ciências sociais. É nesta atitude filosófico-culturalista que se incluem quer o ensaísmo de Eduardo Lourenço (desde o clássico ensaio O labirinto da saudade, 1978), ${ }^{8}$ quer os vários trabalhos do próprio Onésimo Teotónio Almeida. Este tipo de ensaísmo não tem, manifestamente, a preocupação de fixar um "carácter nacional" ou um "ethos português" a que se possa chamar a essência da "portugalidade", distanciando-se assim dos excessos condenáveis do essencialismo.

\section{Articulações entre insularidade e açorianidade: da cultura à litera- tura}

Como nos mostram à saciedade estudos comparatistas, as problematizações identitárias colocam-se hoje a vários níveis e em diversos contextos políticoculturais. A península ibérica revela-se, a este propósito, um caso verdadeiramente singular, sendo objecto de múltiplas abordagens - históricas, sociológicas e culturais, mas também de ordem estético-literária. Os recentes estudos reunidos nos volumes colectivos de Fernando Cabo Aseguinolaza (2010), A comparative history of literatures in the Iberian peninsula; e de Santiago Pérez Isasi e Ângela Fernandes (2013), Looking at Iberia (a comparative European perspective), são disso um esclarecedor exemplo, ao nível de renovadas perspectivas comparatistas que não podem ignorar um debate cultural como o de Onésimo Teotónio Almeida, entre outros contributos. O estudo a e a problematização da literatura não devem ser divorciados de perspectivas histórico-culturais de amplos horizontes.

Como sugerido na parte inicial deste texto, a ilha e a condição da insularidade constituíram-se, frequentemente, como continuado pretexto afectivo e intelectual de questionação do tema da identidade cultural, tema polémico e complexo. Isso é particularmente visível na escrita, sobretudo ensaística, mas também na criação literária, de Onésimo Teotónio de Almeida, autor de origem açoriana, e professor e investigador numa universidade estadunidense, para quem o caso cultural aço-

\footnotetext{
7 Aliás, como observa Onésimo Teotónio Almeida (2009, p. 55), não deixa de ser significativo que também José Gil (2005), no citadíssimo Portugal, hoje: o medo de existir, evite mesmo o marcado conceito de identidade.

8 Em vários momentos, Onésimo Teotónio Almeida debruça-se sobre a singularidade do ensaio de Eduardo Lourenço como escrita de autognose, cuja heterodoxia crítica não visa unanimismos, mas antes o apelo à inquirição constante e obsessiva sobre as questões de identidade (ou de hiperidentidade) cultural portuguesa. Entre outras intervenções, em "Le labyrinthe de l'identité l'héterodoxie d'Eduardo Lourenço” (AlmEIDA, 2013d), o autor detém-se na recepção crítica dessa modalidade de ensaio, dentro e fora de Portugal.
} 
riano se tem revelado um tema verdadeiramente obsessivo, mas em que a relação afectiva não obnubila a clarividência argumentativa.

Em vários dos seus textos, ao longo de algumas décadas - desde os ensaios Açores, açorianos, açorianidade (1989, reeditado em 2011) e A questão da identidade nacional na escrita portuguesa contemporânea (1991); até à peça teatral No seio desse amargo mar (1992), entre outros textos, o discurso reflexivo do autor visa uma persistente indagação identitária, que articula o local ou regional (arquipélago açoriano) com o nacional e até com o universal. E neste contexto coloca a relevante questão - perante as especificidade de uma identidade cultural açoriana pode equacionar-se a existência de uma literatura açoriana? Vamos por partes, porque o debate assim o exige.

Desde logo, o questionamento identitário não poder ser desenvolvido fora desta dialéctica de perspectivas. Nesse sentido, para este estudioso impõe-se algumas reflexões genéricas fundamentais. Desde logo, a identidade cultural é sempre um conceito dinâmico, em construção, pois as sociedades e as culturas são evolutivas, não estáticas. Deve igualmente ser entendida em sentido antropológico, equidistante de visões estreitas, materializando-se num singular conjunto de traços ou idiossincrasia. Para Onésimo T. Almeida e outros autores - independentemente de serem ou não originários dos Açores -, existe uma personalidade ou identidade cultural insular no arquipélago açoriano, assinalada por açorianos e não açorianos, desde Vitorino Nemésio a Raul Brandão (de As ilhas desconhecidas), ao reconhecerse a existência de marcas culturais específicas, configurando uma "mundividência açoriana" - as visões "de dentro" completam-se com as visões "de fora". Essa condição histórico-cultural da insularidade é fruto de várias circunstâncias - históricas, geográficas (distância, isolamento), climáticas e culturais (costumes, religião, etc.), como tem sido assinalado por vários estudiosos, em diversos domínios.

Afinal, estas e outras circunstâncias não podem ser alheias à configuração desta especificidade cultural, pois como refere o próprio Onésimo Teotónio Almeida, para Vitório Nemésio a cultura é indissociável do chão em que nasce. Assim, o reconhecimento e a defesa da açorianidade "não é um bairrismo doentio, mas sim o gostar de ser donde é" (Almeida, 2011a, p. 31-32), isto é, a afirmação de um sentido de pertença a uma realidade cultural específica. Nem muito menos essa afirmação deve ser vista como uma teimosia, mas antes uma realidade que não pode der objecto de ignorância nem de erosão: "ela existe e porque, através dela, se manifesta e se expressa um complexo mundo temático, imagético e emotivo (estético e ético) (AlmeidA, 2011a, p. 136). Também não é sinónimo de fractura ou de independência política do continente, antes a consciência de uma diferença na percepção do mundo, de pertença a uma pátria no sentido clássico do termo.

Desde 1932, pelo menos, o termo e conceito de açorianidade existe na pena de Vitório Nemésio, por analogia com outras designações congéneres (portugalidade, hispanidade) e com o objectivo de significar o conjunto de certas "marcas insulares" que distinguiam ou singularizavam o modo de ser e de estar açoriano do por- 
tuguês continental, sendo a açorianidade a "consciência dessa diferença". A assunção dessa diferença foi lapidarmente enunciada pelo citado Nemésio, quando entre outras coisas escreveu: "Para nós [...] ilhéus inatos, contumazes, açorianidade é o nosso modo de afirmação no mundo, a alma que sentimos no corpo que levamos" (AlmeidA, 2011a, p. 25-26; 29-30). ${ }^{9}$ Assim sendo, para Onésimo Teotónio Almeida, essa identidade cultural açoriana manifesta-se numa expressão literária, já com uma considerável tradição que remonta ao século XIX, pelo menos desde o simbolista finissecular Roberto de Mesquita.

Esta tradição literária desenvolveu-se no contexto do reconhecido centralismo do sistema literário português, ou da sua forma centrípeta - só alcança facilmente representação nesse sistema literário o que acontece em Lisboa, numa lógica dialéctica centro versus periferia. Para a justificada tese do ensaísta, a dinâmica centro/periferia pode ser geradora de certos dinamismo culturais e literários, potenciando a gestação de certas unidades culturais que podem gravitar em redor de um centro, sem pôr em causa a relação de pertença, nem descaracterizar a sua relativa autonomia. Este movimento pode ser acentuado pela distância geográfica ou por outros factores. ${ }^{10}$

Na senda das anteriores reflexões, no pensamento de Onésimo Teotónio Almeida faz então todo o sentido articularem-se os conceitos de identidade nacional (portuguesa, por exemplo) e de identidade cultural de uma região particular como os Açores. Elaborando-se sempre do particular para o geral, do regional para o nacional e para o universal, ${ }^{11}$ a construção da identidade materializa-se em representações simbólicas, sociais e artísticas, como defendido no ensaio "Em busca de clarificação do conceito de identidade cultural - o caso açoriano como cobaia" (Almeida, 1995).

Nesta lógica argumentativa, a identidade cultural açoriana não deixa de fazer parte da identidade nacional portuguesa, mas sem perder a sua marca de especificidade - nos costumes e tradições, na religião e nos rituais, na literatura e nas ou-

9 Aliás, o ensaísta destaca uma precursora conferência de Vitorino Nemésio, "O açoriano e os açores”, proferida em Coimbra, em 1928 e logo publicada pela Renascença portuguesa, acrescentando: "É, todavia, ao longo do segundo quartel do século que Vitorino Nemésio vai dar corpo à ideia de açorianidade como mundividência e vivência particular do povo açoriano, um modo específico de estar no mundo que se expressa, de entre outros modos, com uma determinada sensibilidade literária" (AlmeIDA, 2011a, p. 59).

10 De modo complementar, seria interessante tentar explicar a existência da literatura açoriana no âmbito da literatura portuguesa, num jogo de identidade e de diferença, à luz da teoria dos polissistemas do teórico literário israelita Itamar Even-Zoahar (1999); bem como da contextualização no quadro de outras literaturas regionais europeias (cf. BARBE, 1998).

${ }^{11}$ É nesse movimento dinâmico do particular para o geral que se entende, por exemplo, que possamos falar em identidade cultural açoriana, identidade cultural portuguesa, identidade cultural ibérica ou mesmo europeia. Há mais de um século, Miguel de Unamuno não encontrava paradoxo algum no facto de considerar Camilo o escritor que melhor expressava artisticamente a identidade ou "alma" portuguesa e, ao mesmo tempo, o génio ibérico (cf. MARTINs, 2012). Aliás, na senda de alguns autores portugueses do Oitocentos, como Oliveira Martins e Antero de Quental (cf. AlmeidA, 2012, p. 49). 
tras artes. Por outras palavras, a variada reflexão de Onésimo Teotónio Almeida em torno das questões da identidade cultural e da açorianidade desemboca naturalmente na defesa de uma literatura açoriana, como uma das manifestações legítimas dessa açorianidade. ${ }^{12}$ Contudo, reflexo de uma cultura, a ideia da existência de uma literatura açoriana no quadro do sistema literário português é relativamente recente e não se mostra pacífica, quer no próprio campo cultural açoriano, quer externamente. Com efeito, a existência ou não de uma literatura açoriana levanta uma série de dificuldades e de objecções, a que o pensamento crítico de Onésimo Teotónio Almeida tem respondido ao longo dos anos e em diversas intervenções, pelo menos a partir da década de 1980, sobretudo em dois livros: A questão da literatura açoriana (1983); e Açores, açorianos, açorianidade - um espaço cultural ( $1^{\mathrm{a}} \mathrm{ed}$., 1989). De facto, foi por esses anos que, até por razões de um contexto político específico (projecto de autonomia política dos Açores), que este tema suscitou mais vivo debate; tendo, no entanto, a consequência de o viciar através de uma série de preconceitos, sobretudo o de considerar autonomia sinónimo de independência.

Hoje, solidificado já o processo de autonomia política e arrefecidos os excessos de um discurso político-independentista, enfim, serenados certos fantasmas de ruptura, mostra-se relativamente consensual o reconhecimento de uma identidade cultural açoriana e de uma literatura açoriana, sem os preconceitos ou os ressentimentos de outrora. Entre os factores mais significativos desse processo de institucionalização da literatura açoriana ${ }^{13}$ destacam-se: a intensidade da publicação de livros e autores, quer no arquipélago, quer no espaço alargado da diáspora, incluindo o continente; a crescente publicação de estudos críticos, sob a forma de artigos, ensaio ou teses académicas, em diversas universidades europeias e americanas; relacionadamente, a realização de seminários, jornadas ou de colóquios académicos, dentro e fora do arquipélago; ${ }^{14}$ a publicação de revistas, bem como de ricos e actuantes suplementos culturais e literários na imprensa pe-

12 Tal como no plano nacional, Onésimo Teotónio Almeida (1991) se debruça sobre a escrita portuguesa contemporânea enquanto forma privilegiada de expressão artística e de reflexão crítica sobre a "questão da identidade nacional", sua história e idiossincrasias. Ou seja, a escrita como modo de "pensar Portugal", para usarmos uma expressão muito repetida.

13 "Nada parece impedir que se continue a usar a expressão literatura açoriana independentemente da obrigação de se lhe ter de incluir no significado o sentido de autonomia" (AlmEIDA, 2011a, p. 28). Acrescentando o estudioso que, primeiro, essa expressão tem a vantagem de evitar equívocos desnecessários quando comparada com outras expressões alternativas (como a de "literatura portuguesa de expressão africana"); segundo, que literatura açoriana designa um conjunto de obras que, no panorama português, se distinguem por uma série justificada de características, devidamente enunciadas e identificáveis.

${ }^{14}$ Apenas a título de exemplo, mencionem-se a realização de eventos como: I Simpósio sobre Literatura Açoriana, realizado na Brown University, 1983; e a IX Semana de Estudos do Instituto Açoriano de Cultura (IAC) - entidade responsável por inúmeras publicações relevantes da cultura açoriana, dedicada ao tema "O conhecimento dos Açores através da sua literatura", em 1988. Para uma actualizada síntese da considerável história da literatura açoriana, veja-se o informado estudo de Urbano Bettencourt (2017), traçando a longa gestação e evolução do conceito. 
riódica, numa apreciável tradição da cultura açoriana ainda hoje mantida viva; ${ }^{15}$ last, but not least, a instituição universitária de programas da unidade curricular de Literatura açoriana, primeiro na Universidade de Brown (1978) e depois na Universidade dos Açores (1985).

Gradualmente, o caso idiossincrático dos Açores foi sendo identificado, passando-se da desconfiança e do ressentimento a um generalizado reconhecimento, nacional e internacional. Recorrendo ao argumento de Ludwig Wittgenstein, o uso da expressão "literatura açoriana" em múltiplas circunstâncias, entre escritores, estudiosos e intelectuais, também contribui para a legitimação do seu reconhecimento público. É também essa convicção que permite ao autor afirmar: "entretanto, operou-se também uma institucionalização da cultura açoriana no discurso oficial e na Universidade: a realidade da personalidade cultural insular e a sua expressão literária e artística em geral literária e artística em geral passaram a quase não ser contestadas e são regular e sistematicamente afirmadas e defendidas" (AlmeidA, 2011a, p. 10). Contudo, consciência de algumas resistências, o pensamento de Onésimo Teotónio Almeida insiste fundamentadamente em alguns dos seus argumentos. Assim, visando a legitimidade do uso desta expressão "literatura açoriana" para designar uma criação literária dotada de especificidades culturais e estéticas, um primeiro argumento reiterado pelo autor é de ordem históricofactual: há matéria mais do que suficiente, em termos culturais e estético-literários, para justificar a discussão do assunto; ou seja, existe um corpus muito variado e prolongado no tempo (de Roberto de Mesquita a Eduíno de Jesus, passando por dezenas de escritores dignos de atenção), que atesta a existência de uma literatura singular, materializado num assinável número de publicações - editoras portuguesas (da Editora Salamandra, de Lisboa, à Opera Omnia, no presente), coleções variadas, géneros (narrativa, poesia, ensaio, diário) -, numa criatividade que um leitor atento tem de reconhecer, quer em solo açoriano, quer na extensa diáspora (do continente aos Estados Unidos e ao Canadá, passando pelo Brasil). Como recorda o ensaísta, ao destacar a vastíssima bibliografia do arquipélago, "os Açores têm sido, na expressão de Nemésio, um "viveiro" de escritores" (AlmeidA, 2011a, p. 15).

Por outras palavras, e em consequência, considera-se por isso mesmo o tema digno de toda a reflexão, e não uma questão trivial e esvaziada de pertinência. Para isso acontecer, ergue-se uma condição sine qua non - independentemente de estarem dentro ou fora dos Açores -, os intervenientes neste diálogo de ideias têm de estar devidamente informados sobre a história da cultura açoriana, sob pena de o debate não se poder concretizar, ou então de começar inevitavelmente inquinado por preconceitos de natureza vária. ${ }^{16}$

15 Neste enquadramento, é muito significativo relembrar que, enquanto meio cultural e literário dotado de uma actividade intensa e rica - com as suas elites e grupos, gerações e tertúlias, incluindo também relações de centro/periferia (Angra e Ponta Delgada face a outras cidades) -, os Açores tiveram mais de 600 jornais e revistas (cf. AlmeidA, 2011a, p. 55).

16 Aliás, uma das recorrentes reflexões do autor é justamente em torno das debilidades que habitualmente caracterizam o debate de ideias em Portugal sobre os temas mais diversos, enfermo de 
Neste contexto, a metodologia argumentativa usada por Onésimo Teotónio Almeida é a de analisar criticamente os argumentos pró e contra a existência da literatura açoriana, ao longo das últimas décadas. ${ }^{17}$ Respondendo a algumas objecções formuladas ou possíveis, os principais argumentos sustentados pelo autor centram-se em tópicos como: a génese do termo e conceito; a autonomia da literatura açoriana face à portuguesa; a diversidade dos autores residentes nos Açores ou na diáspora; a história da literatura açoriana em livro; e ainda o balanço ou resultado do debate crítico. Como não podemos aqui detalhar cada um desses tópicos, fique apenas uma brevíssima panorâmica: primeiro, e como sugerido, a génese do termo e conceito de "literatura açoriana" conhece já uma considerável história, pois se a criação literária remonta pelo menos à estética simbolista, a reflexão sobre esta realidade criativa tem sido objecto de estudo por parte de um assinalável conjunto de críticos, no qual o ensaísta se insere de pleno direito. Consabidamente, o campo cultural e literário açoriano beneficiou - de forma reconhecida, mas sem determinismos excessivos - de um certo isolamento geográfico face ao centralismo de Lisboa; bem como de condições decorrentes da sua especificidade histórico-cultural, geográfica e climática $;{ }^{18}$ sem esquecer a maior proximidade do continente americano. Numa palavra, designando uma realidade objectiva, a expressão literatura açoriana está hoje assumida e plenamente institucionalizada: "embora se falasse já em literatura açoriana no século XIX e não faltasse quem nesses termos se referisse à produção literária dos Açores nas primeiras décadas do século, é praticamente Vitorino Nemésio quem funda a ideia de uma expressão açoriana específica manifestada, entre outros meios, através da literatura" (Almeida, 2011a, p. 62).

Já sobre o tópico controverso da autonomia da literatura açoriana face à portuguesa, Onésimo Teotónio Almeida insiste tratar-se de uma questão de perspectiva, já que a ideia de autonomia deve ser entendida de forma relacional, naturalmente. Isto é, existe uma "literatura açoriana" com uma expressão própria ao longo do tempo, sem deixar de estar devidamente integrada no amplo e plural sistema literário português. Repita-se que estamos perante uma identidade cultural que se

alguns vícios lógico-argumentativos e mesmo de um congenial empolamento emocional e floreado oratório. Isso mesmo é realçado, arguta e fundamentadamente, na prolongada conversa filosófica com João Maurício Brás, em Utopias em dói menor (cf. AlmEIDA, 2012, p. 33 et passim).

${ }_{17}$ Em entrevista recente ao jornal Açoriano Oriental (de 8 de Julho de 2013), Onésimo T. Almeida revisitava a questão da legitimidade da literatura açoriana, pesando os vários argumentos a favor e contra e relembrando que mesmo da parte dos mais críticos não tinha surgido uma contraargumentação apreciável: "ainda hoje estou à espera de alguém que venha responder aos argumentos que expus para defender a legitimidade do uso da expressão 'literatura açoriana' no sentido em que expliquei poder e dever usar-se" (AlmeIdA, 2013c).

18 Segundo vários estudiosos, a história, a geografia e o clima açorianos plasmam-se numa consciência e visão próprias, e mesmo num imaginário e metáforas específicas, por exemplo na omnipresença do tema do mar, enquanto realidade que molda a psique ou o carácter do açoriano, numa contaminação quase osmótica entre paisagem, estado de alma e expressão estética, embora longe de ultrapassados determinismos oitocentistas. Sobre este tópico, cf. "Geografia: insularidade e clima. A suposta influência psíquica” (AlmEIDA, 2011a, p. 37- 49). 
materializa numa singular idiossincrasia, assinalada por açorianos ou mesmo por não açorianos - desde Vitorino Nemésio a Raul Brandão -, ao reconhecerem "marcas culturais específicas" (ALMEIDA, 2011a, p.25), configurando assim uma mundividência açoriana no quadro mais englobante da cultura e literatura portuguesas.

Dentro da lógica cultural de que "cada conjunto é sempre um subconjunto de outro maior", para o estudioso a afirmação da diferença da literatura açoriana não é incompatível com a sua pertença ao sistema literário português, entendido este numa concepção plural e integradora: "A literatura açoriana não é independente da portuguesa, uma vez que ela se desenvolve dentro das linhas fundamentais desta", podendo o mesmo escritor ser representativo da tradição literária açoriana, sem deixar de pertencer, de pleno direito, à literatura portuguesa (ALMEIDA, 2011a, p. 91-92). Do afirmado, superadas algumas controvérsias e hesitações, tornase evidente que a literatura açoriana constitui assim um caso único, pelas suas diversas singularidades, no panorama cultural e literário português.

Interrelacionadamente, foram surgindo dúvidas sobre quem são os autores que integram esse património da literatura açoriana: apenas os nascidos e/ou residentes nos Açores? Ou também contempla os escritores e intelectuais que vivem e escrevem fora dos Açores, quer no continente, quer em espaços de emigração como os Estados Unidos? Naturalmente, para Onésimo Teotónio Almeida como para outros estudiosos faz todo o sentido ter aqui uma visão integradora, não excluindo autores apenas com base num critério geográfico. Esse fenómeno ocorre com imensas literaturas, cuja história inclui legitimamente os escritores da diáspora. Aliás, as visões "de dentro" completam-se com as "de fora", numa percepção conjunta da especificidade e da diferença, mas ambas enformadas pela mesma matriz cultural da insularidade.

Ao mesmo tempo, outra perplexidade foi formulada de diversas formas, mais ou menos cépticas e provocatórias: se existe uma história da literatura açoriana por que não foi compendiada em livro até ao momento numa História da Literatura Açoriana? Trata-se, evidentemente, de uma falsa questão, por alguns motivos principais: primeiro, a não existência dessa obra não significa que a literatura açoriana não seja uma realidade história; segundo, em muitos sistemas literários como o português, já existia a consciência de uma literatura autónoma mesmo antes da redação dos primeiros trabalhos históricos sobre ela, com destaque para o incansável e pioneiro labor oitocentista de Teófilo Braga, aliás também ele açoriano. Terceiro, essa história literária já existe, embora de forma disseminada: "ela está escrita em inúmeros pequenos capítulos dispersos por jornais, revistas e livros. Um historiador interessado praticamente quase só terá que recolher, compilar e ordenar apenas toda essa informação. $\mathrm{O}$ desconhecimento da existência dessa história "escrita em fascículos" dispersos não autoriza a que se lhe negue a existência” (AlmEIDA, 2011a, p. 75). Além disso, existem mesmo algumas recolhas literárias, por géneros, cuja publicação foi relevante neste continuado processo de reconhecimento da especificidade cultural açoriana: "de Nemésio para cá, a ideia 
de uma expressão literária da diferença cultural açoriana ganha corpo e legitimidade" (AlmEIDA, 2011a, p. 27).

Finalmente, podemo-nos perguntar sobre qual é o saldo deste prolongado debate em torno da questão da literatura açoriana. ${ }^{19} \mathrm{O}$ balanço é, para Onésimo Teotónio Almeida, bastante positivo, desde logo pelo facto de se considerar hoje a questão com a seriedade que merece. Depois, porque a defesa da legitimidade de uma literatura açoriana não foi contestada até ao momento com argumentos ponderáveis. E torna-se claro que a literatura açoriana assim definida e defendida constitui uma das faces mais visíveis e relevantes dessa mesma cultura, dentro do espaço cultural português. De facto, na senda das brevíssimas reflexões anteriores, podemos inferir que, a perspectiva de Onésimo Teotónio Almeida, espelhando a consciência de uma especificidade cultural e identitária, a literatura açoriana: i) se apresenta como expressão estética da identidade cultural açoriana (idiossincrasia de que os açorianos têm consciência há muito); ii) comporta uma tradição literária específica, longa, diversificada e dinâmica, expressa em vários géneros (poesia, narrativa, teatro, diário, ensaio, etc.), parcialmente recolhida em diversas antologias; ${ }^{20}$ iii) proporciona legítimas tentativas de caracterização tipológica dos açorianos, na sua diversidade e singularidade cultural; iv) revela uma "intensa actividade literária”, desde o século XIX até hoje; v) beneficiou enormemente do continuado labor de incansáveis estudiosos e divulgadores, em que se destacam vários nomes, incluindo o de Onésimo Teotónio Almeida.

\section{Concluindo}

É recomendável concluirmos esta brevíssima sistematização sobre um tema muito caro ao ensaísmo de Onésimo Teotónio Almeida. Identidade cultural, insularidade e literatura apresentam afinidades que podem ser demonstráveis, como se procurou apresentar em tão curta exposição sobre o pensamento do autor neste matéria. Não é recomendável pensar a identidade cultural de uma comunidade ou território fora de um conjunto de cautelas crítico-hermenêuticas. Também aqui se deve inserir a questão da existência da literatura açoriana.

"A ilha acentua a minha solidão"; e ainda: "esta ilha é o meu derradeiro combate com a besta”, escreveu Paulo José Miranda (2001, p. 59, 92) em Vício, diário ficcio-

\footnotetext{
19 Saliente-se que Onésimo Teotónio Almeida é um dos professores que desenvolvem academicamente um curso de pós-graduação justamente sobre literatura açoriana, na Universidade de Brown, sumariamente apresentado pelo próprio nestes termos: "que no fundo é sobe a cultura açoriana através da literatura, curso que surgiu para satisfazer o interesse de alunos destinados ao ensino em escolas onde existiam alunos emigrantes portugueses, oriundos sobretudo dos Açores" (ALMEIDA, 2012, p. 160).

${ }^{20}$ Como a de Pedro da Silveira, Antologia da poesia açoriana (1977), ou, sobre esta problemática, Para uma literatura açoriana, de José Martins Garcia (1987), apenas a título de exemplo; a par de estudos críticos que, sem preocupações de exaustividade, antes de amostra ilustrativa, sistematizam os principais valores da tradição literária açoriana, antes e depois de 1974 (cf. AlmEIDA, 2011a, p. 10-12, 55-76 et passim), nomeadamente em "Quadro panorâmico da literatura açoriana dos últimos cinquenta anos (1940-1989)".
} 
nado do deprimido e açoriano Antero de Quental, acentuando assim imagem do intelectual desistente, imbuído do pessimismo finissecular, mais precisamente no ano fatídico do seu suicídio, em 1891. Ora, em perspectiva distinta, já na obra criativa No seio desse amargo mar, Onésimo Teotónio Almeida (1992) se tinha inspirado nesta personalidade tutelar da cultura e literatura portuguesas, e em outras figuras da cultura e literatura açorianas, para indagar a questão da existência de uma marca específica ou identidade açoriana no seio da cultura nacional. Com efeito, a referida peça teatral estrutura-se em três actos, sendo o primeiro e o terceiro preenchidos por uma singular e humorada tertúlia post mortem de um variado conjunto de figuras da cultura açoriana, situados numa Atlântida mítica. Esta foi também uma forma artístico-simbólica de Onésimo Teotónio Almeida, na sua vertente criativa, se debruçar sobre o tema da existência de uma literatura, entendida como reflexo da açorianidade. Em suma, a descentralização e individualidade da cultura açoriana pode ser geradora de uma literatura singular, no quadro mais alargado da pluralidade e diversidade da cultura e da literatura portuguesas.

\section{Referências}

Almeida, Onésimo Teotónio, A questão da literatura açoriana. Angra do Heroísmo: Secretaria Regional da Educação e Cultura, 1983.

Almeida, Onésimo Teotónio. Filosofia Portuguesa - alguns equívocos. Cultura, História e Filosofia, vol. VI, Lisboa: Inst. Nac. de Investigação Científica, p. 219-255 1985. (in Almeida, 2017, p. 153-193).

Almeida, Onésimo Teotónio. A questão da identidade nacional na escrita portuguesa contemporânea. Hispania, Vol. LXXIV, n. 3, p. 492-500, 1991 (in Almeida, 2017, p. 29-48).

Almeida, Onésimo Teotónio. No seio desse amargo mar. Lisboa: Ed. Salamandra, 1992.

Almeida, Onésimo Teotónio. Identidade cultural: desdobrando polissemias em busca de clareza. In Hermenegildo Fernandes et alii (eds.). Nação e Identidades Portugal, os Portugueses e os Outros. Lisboa: Caleidoscópio, 51-63, 2009 (in Almeida, 2017, p.71-92).

Almeida, Onésimo Teotónio. Açores, Açorianos, Açorianidade - um espaço cultural. $2^{a}$ ed. Angra do Heroísmo: Instituto Açoriano de Cultura [1 ${ }^{\mathrm{a}}$ ed., 1989], $2011 \mathrm{a}$.

Almeida, Onésimo Teotónio. Utopias em Dói Menor:conversas transatlânticas com Onésimo. Lisboa: Gradiva, 2012.

Almeida, Onésimo Teotónio. Ilhas e continentes, mentalidade insular e identidades: à conversa com Onésimo Teotónio Almeida [entrevista]. Supl. Artes e Letras do jornal Terra Nostra, 7 de Junho. II-IV, 2013b. 
Almeida, Onésimo Teotónio. Memória do tempo: conversa com Onésimo T. Almeida sobre açorianidade e literatura [entrevista de Vamberto Freitas]. Jornal Açoriano Oriental, 8 de Julho, 2013c.

Almeida, Onésimo Teotónio. Le labyrinthe de l'identité - l'héterodoxie d'Eduardo Lourenço. In: Maria Graciete Besse (org.). Eduardo Lourenço et la Passion de l'Humain. Paris: Éd. Convivium Lusophone, 99-111, $2013 \mathrm{~d}$.

Almeida, Onésimo Teotónio. A obsessão da portugalidade: identidade, língua, saudade \& valores. Lisboa: Quetzal, 2017.

Anderson, Benedict. Imagined Communities. London / New York: Verso. 1991.

BARBE, J. Paul. Place des littératures regionales en Europe. In: Béatrice Didier (dir.), Precis de Littérature Européenne. Paris: P.U.F., 1998.

Bettencourt, Urbano. O Amanhã não Existe: Inquietação Insular e Figuração Satírica em José Martins Garcia. Lages do Pico: Companhia das Ilhas, 2017.

BhabBa, Homi B. Nation and Narration. London - New York: Routledge, 1990.

Barata, André et alii (org.). Representações da Portugalidade. Lisboa: Caminho, 2011.

Even-Zoahar, Itamar. Teoría de los Polisistemas. Madrid, Arco Libros, 1999.

Cabo Aseguinolaza, Fernando et alii (ed.). A Comparative History of Literatures in the Iberian Peninsula. Amsterdam / Philadelphia: John Benjamins, 2010.

CAvagna, Mattia (org.). Les Lettres Romannes - L'île dans la Littérature. Tome 66, $1-2,3-156,2012$

Garcia, José Martins. Para uma Literatura Açoriana. Ponta Delgada: Universidade dos Açores, 1987.

GiL, José (2005). Portugal, Hoje: O Medo de Existir. $5^{\text {a }}$ ed. Lisboa: Relógio d'Água, 2005.

Lourenço, Eduardo. O Labirinto da Saudade (Psicanálise Mítica do Destino Português). $2^{\mathrm{a}}$ ed. Lisboa: D. Quixote 1982 [1 ${ }^{\mathrm{a}}$ ed., 1978].

MANGuel, Alberto \& GuAdalupi, Gianni. Dicionário de Lugares Imaginários. Lisboa: Tinta da China. 2013.

Martins, José Cândido de Oliveira. Camilo Castelo Branco e as imagens de Portugal em Miguel de Unamuno: lusofilia, representações e aporias. In: $M^{a}$ Jesús Fernández García \& $\mathrm{M}^{\mathrm{a}}$ Luísa Leal (coord.). Imagologías Ibéricas: construyendo la imagen del otro peninsular. Mérida: Gabinete de Iniciativas Transfronterizas / Gobierno de Extremadura, pp. 163-18o, 2012.

MARTINs, José Cândido de Oliveira. A literatura como revelação do génio nacional em Teixeira de Pascoaes - intuições e aporias. In: Sofia A. Carvalho et alii (coord.), 
Teixeira de Pascoaes, vol. 2 (A Arte de Ser Português e a Renascença Portuguesa), Lisboa, Colibri, pp. 273-288, 2017.

Matroso, José. A Identidade Nacional. Lisboa: Gradiva, 2001.

Miranda, Paulo José. Vício. Lisboa: Cotovia, 2001.

PÉrez Isasi, Santiago \& Fernandes, Ângela. Looking at Iberia (A Comparative European Perspective). Peter Lang: Oxford - Berlin - Bruxelles - Frankfurt am Main - New York - Wien, 2013.

ReAL, Miguel. O Pensamento Português Contemporâneo (189o-2010). Lisboa: IN-CM, 2011.

Santos, Boaventura de Sousa. Pela Mão de Alice (O Social e o Político na PósModernidade). $7^{\mathrm{a}}$ ed., Lisboa: Afrontamento, 1999 [1 $1^{\mathrm{a}}$ ed., 1994].

Silveira, Pedro da. Antologia da Poesia Açoriana. Lisboa: Liv. Sá da Costa, 1997.

Smith, Anthony (1991). National Identity. Reno: Univ. of Nevada Press, 1991.

ThIEsse, Anne-Marie. A Criação das Identidades Nacionais: Europa - Séculos XVIIIXX. Lisboa: Temas e Debates, 2000.

Recebido em 8 de junho de 2021.

Aprovado em 28 de junho de 2021.

\section{Resumo}

Insularidade e identidade em Onésimo Teotónio Almeida: da cultura à literatura

\section{José Cândido de Oliveira Martins}

A ilha e a condição da insularidade, face ao continente, constituíram-se, frequentemente, como continuado pretexto afectivo e sobretudo intelectual para questionação do complexo tema da identidade cultural (regional, nacional ou supranacional), tema polémico e complexo. Isso é particularmente visível na escrita, sobretudo ensaística, mas também literária, do escritor português Onésimo Teotónio de Almeida. Em várias das suas publicações, ao longo de algumas décadas desde os ensaios aos textos criativos - o discurso reflexivo deste autor visa uma persistente indagação identitária, que articula o local ou regional com o nacional e até o universal, abarcando os sistemas da cultura e da literatura.

Palavras-chave: identidade cultural, ilha, literatura nacional, Onésimo Teotónio de Almeida. 